\title{
Varikoselektomi prematür ejakülasyonda tedavi seçeneği olabilir mi?
}

\section{Can varicocelectomy be a treatment option in premature ejaculation?}

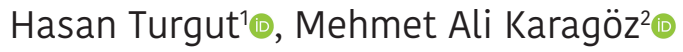

\section{öz}

AMAC̦: Prematür ejakülasyon erkeklerde oldukça sık rastlanan cinsel fonksiyon bozukluklarından biridir. Klinik varikoseli olan hastalarda da prematür ejakülasyon sıklıkla görülebilmektedir. Çalışmamızda varikoselektominin prematür ejakülasyon üzerindeki etkisini araştırdık.

GEREC ve YÖNTEMLER: Ekim 2018 ve Mart 2020 tarihleri arasında klinik varikosel nedeni ile opere edilen ve prematür ejakülasyonu olan hastalar prospektif olarak çalışmaya dahil edildi. Tüm hastalara mikroskopik subinguinal varikoselektomi yapıldı. Premature Ejaculation Diagnostic Tool (PEDT) ölçeğinin Türkce valide formu ile vajen içi ejakülasyon gecikme zamanı (intravaginal ejaculatory latency time - IELT) verileri işlemden önce ve işlemden 6 ay sonra olmak üzere kaydedildi ve karşılaştırılma yapıldı.

BULGULAR: Çalışmaya toplam 64 hasta dahil edildi. Cerrahi öncesi hastaların ortalama IELT süresi $32.4 \pm 4.2$ iken postoperatif 6 .ayda bu süre $134.6 \pm 17.3$ saniyeye çıktı ve istatiksel olarak anlamlı derecede artış mevcuttu $(\mathrm{p}<0.001)$. PEDT skorlarına bakıldığında ise işlem öncesi $14.2 \pm 4.8$ iken işlem sonrası bu değerin $6.68 \pm 3$.2'e düştüğü gözlendi ve bu değerde de istatiksel olarak anlamlı fark mevcuttu ( $<<0.001)$.

SONUÇ: Çalışmamızda, klinik varikosel ile birlikte prematür ejakülasyonu olan hastalarda varikoselektomi sonrası ejakülasyon sürelerinde anlamlı artış tespit ettik. Varikoselektomi, farmakolojik tedavi ve davranış tedavisiyle beraber uygun endikasyonlarda prematür ejakülasyon tedavisinde yerini alabilir.

Anahtar Kelimeler: prematür ejakülasyon, vajen içi ejakülasyon gecikme zamanı, varikosel

\section{Giriș}

Varikosel, testisi drene eden pampiniform pleksusun anormal dilatasyonu ile karakterize olup, spermatogenezisde bozulmaya yol açarak infertiliteye neden olan bir hastalıktır.

${ }^{7}$ Avrasya Üniversitesi, Sağlık Bilimleri Fakültesi, Medikalpark Karadeniz Hastanesi, Üroloji, Trabzon, Türkiye

${ }^{2}$ Kafkas Üniversitesi Tıp Fakültesi, Üroloji Bölümü, Kars, Türkiye

\section{Yazışma Adresi/ Correspondence:}

Dr. Öğr. Üyesi Hasan Turgut

Medikalpark Karadeniz Hastanesi Üroloji Bölümü, 61000 Trabzon, Türkiye

Tel:

+905059345825

E-mail:drhasanturgut@hotmail.com

Geliş/ Received: $\quad 15.12 .2020$

Kabul/ Accepted: 11.01 .2021

\section{ABSTRACT}

OBJECTIVE: Premature ejaculation is one of the most common sexual dysfunction in men. Premature ejaculation can often be seen in patients with clinical varicocele. In our study, we investigated the effect of varicocelectomy on premature ejaculation

MATRERIAL and METHODS: Between October 2018 and March 2020, patients with premature ejaculation who were operated for clinical varicocele were enrolled in the study, prospectively. Microscopic subinguinal varicocelectomy was performed in all patients. The data of the Turkish validated form of the Premature Ejaculation Diagnostic Tool (PEDT) and intravaginal ejaculatory latency time (IELT) were recorded before and 6 months after the procedure and compared.

RESULTS: A total of 64 patients were included in the study. While the mean IELT duration of the patients before surgery was $32.4 \pm 4.2$, this duration increased to $134.6 \pm 17.3$ seconds in the postoperative 6th months, the difference was found to be statistically significant $(\mathrm{p}<0.001)$. When the PEDT scores were evaluated, it was determined that while it was $14.2 \pm 4.8$ before the procedure, this value decreased to $6.68 \pm 3.2$ after the procedure and there was a statistically significant difference in this value. $(\mathrm{p}<0.001)$.

CONCLUSION: In this study a significant improvement was determined in ejaculatory time after varicocelectomy in patients with premature ejaculation with clinical varicocele. Varicocelectomy, can be offered in the treatment of premature ejaculation in appropriate indications, along with pharmacological and behavioral therapy

Keywords: intravaginal ejaculatory latency time, premature ejaculation, varicocele

Düzeltilebilir infertilitenin en sık nedeni olarak da bilinir. [1,2] Varikosel, yetişkin erkeklerin yaklaşık \%15'inde bulunur, primer infertilitesi olan erkeklerin ise $\% 35^{\prime}$ inde mevcuttur. ${ }^{[3]}$ Tedavisinde ise subinguinal mikroskopik varikoselektomi altın standart tedavidir. ${ }^{[4]}$ Uluslararası seksüel tıp derneği (ISSM) yaşam boyu prematür ejakülasyonu (PE), intravajinal ejakülatuar latens süresinin (IELT) 1 dakika veya daha az olması ve ejakülasyonda kontrol kaybı sonucu sıkıntı, endişe, ve seksüel istekte azalma olarak tanımlamıştır. ${ }^{[5]}$ Yapılan çalışmalarda PE'nin bireyde özgüven kaybı, cinsel tatminsizlik ve cinsel kaçınma davranışlarına yol açtığı gösterilmiştir. ${ }^{[6]}$ Ülkemizde 603 katılımcı ile gerçekleştirilen bir çalışmada toplumdaki PE sıklığının \%36,5, 1412 kişinin dâhil edildiği bir başka çalışmada ise \%25,7 
olarak rapor edilmiştir. ${ }^{[7,8]}$ Son 20 yılda varikosel ve prematüre ejakülasyon birlikteliği bazı yazarların dikkatini çekmiş ve bu ilişki sınırlı sayıda çalışmada gösterilmiştir ancak bu ikili arasındaki ilişki tam olarak aydınlatılamamıştır. [9-11] Çalışmamızda klinik varikoseli ve prematür ejakülasyonu olan hastalarda mikroskobik varikoselektominin prematür ejakülasyon üzerine etkisini inceledik.

\section{GEREÇ ve YÖNTEMLER}

Etik kurul onayı alındıktan sonra (etik onay no: 2018/271) Ekim 2018 ile Mart 2020 tarihleri arasında üroloji kliniğine infertilite ile başvuran ve klinik varikosel tanısı ile mikroskobik subinguinal varikoselektomi uygulanan 157 hasta prospektif olarak değerlendirildi. Hastaların yaş aralığı 20-35 arasında idi. Hastalar aynı zamanda prematür ejakülasyon (PE) açısından 'Premature Ejaculation Diagnostic Tool (PEDT)' ölçeğinin Türkce valide formu kullanılarak değerlendirildi. ${ }^{[12]}$ PEDT skoru $\geq 9$ olan ve varikoselektomi öncesi vajen içi ejakülasyon gecikme zamanı (intravaginal ejaculatory latency time - IELT) $<1 \mathrm{dk}$ olanlar prematür ejakülasyon olarak değerlendirildi. Varikosel tanısı üroloji hekimi tarafindan oda isısında $\left(23^{\circ} \mathrm{C}\right)$, ayakta muayene edilerek valsalva manevrasıyla skrotal muayene yapılarak konuldu. Çalışmaya dahil edilen prematür ejakülasyonu bulunan ve mikroskobik varikoselektomi uygulanan bütün hastalarda grade 2 veya grade 3 varikosel ve en az bir sperm parametresi bozukluğu mevcuttu. Tüm hastalara IIEF-5 formu dolduruldu. Dişlama kriterleri olarak, hastaların PEDT toplam skoru $<9$ ve IELT $\geq 1 \mathrm{dk}$ olması, edinsel prematür ejakülasyon hastaları (IELT $<3$ dakika), hiperprolaktinemi, erektil disfonksiyon (IIEF-5<22), hipogonadotropik hipogonadizm, 3 ay önceden antidepresan kullanımı, prematür ejakülasyon için oral, topikal veya davranış tedavisi alması, eksternal genital malformasyonu veya nüks varikoseli olması ile ürolojik enfeksiyonu ve pelvik bölge cerrahisi öyküsü bulunması belirlendi ve 93 hasta çalışma dışı bırakıldı.

Tüm hastalardan skrotal patolojileri ayırt etmek için skrotal doppler ultrasonografi, preoperatif dönemde iki farklı tarihte aynı laboratuvarda yapılmış spermiyogram örneği ve hormonal parametreler (Folikül stimülan hormon, prolaktin, testosteron, lüteinizan hormon) alındı. Postoperatif 6. ayda hormon paneli, testis hacimlerini değerlendirmek için skrotal ultrasonografi istendi. Tüm hastalara mikroskobik subinguinal varikoselektomi cerrahisi uyguland (X10-X20 büyütme). Hastaların PEDT ve IELT değerleri varikoselektomiden 6 ay sonra işlem öncesiyle karşılaştırıldı. Çalışma öncesinde bütün hastalara çalışmanın amacı ve aşamaları anlatılarak yazılı aydınlatılmış onam formu alındı.

\section{İstatistiksel Analiz}

Normal dağılımı değerlendirmek için, tüm sürekli değişkenleri Kolmogorov-Smirnov testi ve histogram aracılığıyla analiz ettik. Değişkenleri karşılaştırmak için WilcoxonRank testini kullandık. Ayrıca, çalışmada elde edilen verileri SPSS for Windows 20.0 sürümünü kullanarak istatistiksel olarak analiz ettik.

\section{SONUÇLAR}

Klinik varikoseli ve PE'si olan toplam 64 hasta çalışmaya dahil edildi. Hastaların demografik özellikleri Tablo 1'de özetlenmiştir. Hastaların 40'ında solda, 16'sında sağda, 8 'inde ise bilateral varikosel vardı. Toplam 28 skrotal ünitede grade 2, 44 skrotal ünitede grade 3 varikosel mevcuttu (Tablo 1). İşlem sonrası hiçbir hastada komplikasyon görülmedi. Cerrahi öncesi hastaların ortalama IELT süresi $32,4 \pm 4,2$ iken postoperatif 6 . ayda bu süre $134,6 \pm 17,3$ saniyeye çıktı ve istatiksel olarak anlamlı derecede artış saptandı $(\mathrm{p}<0,001)$. PEDT değerlerine bakıldığında işlem öncesi $14,2 \pm 4,8$ iken işlem sonrası bu değerin $6,68 \pm 3,2$ 'e düştüğü gözlendi ve bu değerde de istatiksel olarak anlamlı fark mevcuttu $(p<0,001)$. İlişki sıklığına bakıldığında ise cerrahi öncesi ve cerrahi sonrası herhangi bir fark gözlenmedi $(\mathrm{p}=0,26)$ (Tablo 2$)$. Hastaların preoperatif ve postoperatif 6 . ayda hormon değerlerinde (FSH, LH, testosteron ve prolaktin) ve testis hacimlerinde istatiksel açıdan fark gözlenmedi (Tablo 3). Postoperatif 6. ayda yapılan fizik muayeneler normal olarak gözlendi. Tüm hastaların spermiyogram parametrelerinin bir veya birkaçında (sayı, hareket, morfoloji) düzelme gözlendi.

Tablo 1. Hastaların demografik özellikleri

\begin{tabular}{lc}
\hline Demografik özellikler & Sonuç \\
\hline Yaş (yıl, ort \pm SD) & $26,3 \pm 7,2$ \\
Vücut kitle endeksi $\left(\mathrm{VKi}, \mathrm{kg} / \mathrm{m}^{2}\right)$ & $22,6 \pm 1,8$ \\
Varikosel derecesi ve yönü (skrotal ünite) & \\
Grade 2 & 28 \\
Grade 3 & 44 \\
Sağ & 24 \\
Sol & 48 \\
\hline
\end{tabular}

Tablo 2. Hastaların IELT ve PEDT değerlerinin karşılaştırılması

\begin{tabular}{lccc}
\hline & Preop & Postop 6. ay & P değeri \\
\hline PEDT & $14,2 \pm 4,8$ & $6,68 \pm 3,2$ & $\mathrm{p}<0,001$ \\
IELT (saniye) & $32,4 \pm 4,2$ & $134,6 \pm 17,3$ & $\mathrm{p}<0,001$ \\
iliş̧i sıklığı & $6,4 \pm 3,2$ & $6,5 \pm 4,1$ & $\mathrm{p}=0,26$ \\
\hline
\end{tabular}


Tablo 3. Hormonal parametreler ve testis hacmi değerleri

\begin{tabular}{lccc}
$\begin{array}{l}\text { Hormonal Parametreler ve } \\
\text { Testis Hacmi }\end{array}$ & Preop & $\begin{array}{c}\text { Postop } \\
6 . \text { ay }\end{array}$ & $\begin{array}{c}P \\
\text { değeri }\end{array}$ \\
\hline $\begin{array}{l}\text { FSH (folikül stimülan hormon) } \\
\text { (mlU/ml) (ort } \pm \text { SD) }\end{array}$ & $7,78 \pm 3,4$ & $8,61 \pm 2,6$ & $>0,05$ \\
$\begin{array}{l}\text { LH (lüteinizan hormon) } \\
\text { (mlU/ml) (ort } \pm \text { SD) }\end{array}$ & $3,4 \pm 1,8$ & $3,7 \pm 2,1$ & $>0,05$ \\
$\begin{array}{l}\text { Prolaktin (ng/mL) (ort } \pm \text { SD) } \\
\text { Testosteron (nmol/L) }\end{array}$ & $11,2 \pm 4,6$ & $11,6 \pm 3,8$ & $>0,05$ \\
(ort \pm SD) & $5,7 \pm 2,6$ & $6,2 \pm 1,4$ & $>0,05$ \\
Testis Hacmi (cc, ort \pm SD) & $16,8 \pm 7,2$ & $17,4 \pm 5,2$ & $>0,05$ \\
\hline
\end{tabular}

\section{TARTIȘMA}

Prematür ejakülasyon (PE) erkekler için oldukça ciddi bir sorun olmakla beraber cinsel tatminsizlik, seksüel ilişkide yetersizlik düşüncesi ve neticesinde seksüel disfonksiyona ve eşler arasında problemlere neden olabilmektedir. Çalışmamızda klinik varikosel ile birlikte prematür ejakülasyonu olan hastalarda varikoselektomi sonrası IELT sürelerinde anlamlı derecede artış olduğu gözlenmiştir. $\mathrm{Bu}$ sonuçlar daha önce Asadpour ve ark. ile Ahmed ve ark.'nın yaptığı çalışma ile uyumludur. ${ }^{[13,14]}$ PE nedenleri araştırıldığında uzun yıllar boyunca psikolojik temelli olduğu düşünülmüştür. Etiyolojide düşünülen durumların çoğu kanıta dayalı değildir. Erken cinsel deneyim, anksiyete, seksüel teknik, seksüel aktivitenin sıklığı gibi sebepler psikolojik teoriler olarak sayılmaktadırlar. ${ }^{[15]}$ Psikolojik temelli olarak düşünülmesinin altında anksiyete ile artan sempatik sinir sistem aktivasyonunun daha erken emisyon ve ejakülasyona neden olduğu düşüncesidir. Anksiyete ile ilişkisinin bakıldığı çalışmalarda PE prevalansının daha fazla olduğu görülmüştür. ${ }^{[16,17]}$ Organik teoriler arasında penil hipersensitivite, hipereksitasyonlu ejakulatuar refleks (hızlı emisyon ve hızlı ekspulsiyon fazı, artmış bulbokavernöz refleks), genetik predispozisyon (birinci derece akrabalarda daha fazla görülmekte) ve santral 5 HT reseptör sensitivitesi (muhtemelen düşük 5 HT nörotransmisyonu, 5 HT2 c reseptör hiposensivitesi ve/veya 5 HT1a reseptör hipersensitivitesi) düşünülmektedir. ${ }^{[18,19]}$ SSRI'larla yapılan oral farmakolojik tedavi, PE tedavisinin temelini oluşturmaktadır. Seratonin hormonu, ejakülasyonda santral sinir sisteminde inhibitör rol oynamakta ve bu etkinin SSRI'larla güçlendiği görülmektedir. ${ }^{[20]}$ SSRI alımından birkaç gün sonra etki başlamakta ve maksimum etki 1-2 haftayı bulmaktadır. Yaşam boyu PE tedavisinde SSRI'lar birinci basamak tedavi olarak öne çıkmaktadır. [21,22] Davranış tedavileri incelendiğinde Semans tarafından tarif edilen 'Dur-Başla' programı ve 'sıkma' tekniği gösterilebilir. ${ }^{[23]} \mathrm{Bu}$ uygulamalar kısaca hastanın koitus s1rasında ejakülasyondan hemen önce vaginal penetrasyonu sonlandırması veya kendi kontrolü ile ejakülasyonu ertelemesi prensibine dayanmaktadır. İlişki öncesi mastürbasyon uygulanmasının da benzer etkisi olduğu görülmüştür. [24] Varikosel ve prematür ejakülasyon arasındaki ilişki oldukça karmaşık ve henüz tam aydınlatılabilmiş değildir. Ancak genital bölgedeki lokal sıcaklık artışı ve muhtemelen uyarı artışı ve hipotalamus-hipofiz-gonadal hormonal değişikliğinde etkili olabileceği söylenmiştir. ${ }^{[25]}$ Lotti ve ark.'nın yaptığı çalışmada varikoseli bulunan hastalarda PE oranı (\%29,4), varikoseli bulunmayan hastalardaki PE oranından (\%24,9) anlamlı olarak yüksek bulunmuştur. Ancak bu çalışmada varikosel operasyonu sonrası PE arasındaki ilişkiyi ortaya koyan veri sunulmamıştır. ${ }^{[11]}$ Ahmed ve ark.'nın yaptığı çalışmada ise varikoselektomi sonrası testosteron hormonunun artışıyla bu hastalarda prematür ejakülasyonda düzelme raporlanmıştır. ${ }^{[14]}$ Ancak testosteron hormonunun PE ile ilişkisi tartışmalıdır. Hatta varikosel ve varikoselektomi ile serum testosteron seviyesi arasındaki ilişki tam olarak açıklığa kavuşmuş değildir. [26,27] Li ve ark.'nın yapmış olduğu bir çalışmada yazarlar hem IELT <2 dakika olan grupta hem de IELT > 2 dakika olan grupta postoperatif 6. ay IELT sürelerinde anlamlı artış rapor etmişlerdir. ${ }^{[28]}$ Yine başka bir çalışmada varikosel operasyonu sonrası 3. ayda ölçülen IELT süresinde artış izlenmesine karşın, aradaki süre farkı anlamlı bulunmamıştır. Yazarlar bu sonucu operasyon sonrası kontrol zamanının kısalığından kaynaklandığını bildirmişlerdir. [29] Literatürde prematür ejakülasyon ve varikosel ilişkisini gösteren az sayıda çalışma mevcuttur. Bizim çalışmamızda da klinik varikoseli ile birlikte PE'si olan hastaların cerrahi sonrası 6. ayda IELT sürelerinde ve PEDT değerinde ciddi düzeyde düzelme gözlenmiştir. Ancak, varikosel ve PE arasında ilişkiyi ve varikoselektomi sonrası görülen düzelmenin patofizyolosini açıklayabilmek için moleküler düzeyde çalışmalara ihtiyaç duyulmaktadır.

Çalışmanın limitasyonlarına bakıldığında IELT süresinin tahmini olması veri toplama kaynaklı yanlılığa sebep olmuş olabilir. Göreceli olarak katılımcı sayısının az olması ayrıca preoperatif ve postoperatif dönemde erkek ve kadın cinsel fonksiyonlarının ve cinsel tatmin olma düzeylerinin validiye formlarla değerlendirilmemiş olması çalışmanın kısıtlılıkları olarak sayılabilir.

Sonuç olarak; çalışmamızda varikoselektomi sonrası prematür ejakülasyonun anlamlı derecede düzeldiğini tespit ettik. Ancak prematür ejakülasyonda uygun hastalarda tedavi seçeneği olabilmesi için çok merkezli, randomize, kontrollü klinik çalışmalara ihtiyaç vardır. 
Etik Kurul Onayı

Çalışma, Medikalpark Karadeniz Hastanesi Etik Kurulu tarafından onaylandı.

(onay tarihi ve sayısı: 2018/271).

Hakem Değerlendirmesi

Dış bağımsız.

Çıkar Çatışması

Yazarlar çıkar ilișkisi olmadığını beyan etmișlerdir.

\section{Finansal Destek}

Herhangi bir mali destek alınmamıştır.

\section{Ethics Committee Approval}

The study was approved by Medikalpark Karadeniz Hospital Ethics Committee.

(date and number of approval: 2018/271).

\section{Peer-review}

Externally peer-reviewed.

Conflict of Interest

No conflict of interest was declared by the authors.

\section{Financial Disclosure}

No financial support has been received.

\section{KAYNAKLAR}

1. Jensen CFS, Østergren P, Dupree JM, Ohl DA, Sønksen J, Fode M. Varicocele and male infertility. Nat Rev Urol 2017;14:523-33. [CrossRef]

2. Masson P, Brannigan RE. The varicocele. Urologic Clinics of North America. Urol Clin North Am 2014;41:129-44. [CrossRef]

3. Wein A, Kavoussi L, Alan P, Peters C. Campbell-Walsh Urology, 11th ed. Philadelphia, PA: Elsevier Saunders; 2016.

4. Khera M, Lipshultz LI. Evolving Approach to the Varicocele. Urol Clin North Am 2008;35:183-9. [CrossRef]

5. McMahon CG, Althof SE, Waldinger MD, Porst H, Dean J, Sharlip ID, et al. An evidence-based definition of lifelong premature Ejaculation: Report of the international society for Sexual medicine (ISSM) ad hoc committee for the definition of premature ejaculation. J Sex Med 2008;5:1590-606. [CrossRef]

6. Kempeneers P, Andrianne R, Bauwens S, Georis I, Pairoux JF, Blairy S. Functional and psychological characteristics of belgian men with premature ejaculation and their partners. Arch Sex Behav 2013;42:51-66. [CrossRef]

7. Tekdoğan Ü, Güngör S, Aslan Y, Çanaklı F, Aksüt $H$, Atan A. Türk erkeklerinde cinsel fonksiyon bozukluğu taraması. Üroloji Bült 2003;14:188-92. https://app.trdizin.gov.tr/makale/ TWpNME5EZzQ

8. Balcı M, Aslan Y, Aydın AÖ, Kayalı M, Altuğ Tuncel AA. Türk erkeklerinde cinsel fonksiyon bozukluğu taraması: Anket çalışması. Ortadoğu Tip Derg 2012;4:108-13.

9. Younes AKH. Low plasma testosterone in varicocele patients with impotence and male infertility. Arch Androl 2000;45:187-95. [CrossRef]

10. Ketabchi AA, Ahmadinejad M. Premature Ejaculation in the Varicocele Patients. Shiraz E-Medical J 2008;29:9. https://sites. kowsarpub.com/semj/articles/78549.html

11. Lotti F, Corona G, Mancini M, Biagini C, Colpi GM, Innocenti $\mathrm{SD}$, et al. The association between varicocele, premature ejaculation and prostatitis symptoms: Possible mechanisms. J Sex Med 2009;6:2878-87. [CrossRef]
12. Serefoglu EC, Cimen HI, Ozdemir AT, Symonds T, Berktas M, Balbay MD. Turkish validation of the premature ejaculation diagnostic tool and its association with intravaginal ejaculatory latency time. Int J Impot Res 2009;21:139-44. [CrossRef]

13. Asadpour AA, Aslezare M, Adkani LN, Armin M, Vojdani M. The effects of varicocelectomy on the patients with premature ejaculation. Nephrourol Mon 2014;6:15991. [CrossRef]

14. Ahmed AF, Abdel-Aziz AS, Maarouf AM, Ali M, Emara AA, Gomaa A. Impact of varicocelectomy on premature ejaculation in varicocele patients. Andrologia 2015;47:276-81. [CrossRef]

15. McMahon CG. Premature ejaculation. Indian J Urol 2007;23:97108. [CrossRef]

16. Corona G, Petrone L, Mannucci E, Jannini EA, Mansani R, Magini A, et al. Psycho-biological correlates of rapid ejaculation in patients attending an andrologic unit for sexual dysfunctions. Eur Urol 2004;46:615-22. [CrossRef]

17. Corona G, Mannucci E, Petrone L, Ricca V, Balercia G, Giommi $\mathrm{R}$, et al. Psycho-biological correlates of free-floating anxiety symptoms in male patients with sexual dysfunctions. J Androl 2006;27:86-93. [CrossRef]

18. Waldinger MD. The neurobiological approach to premature ejaculation. J Urol 2002;168;2359-67. [CrossRef]

19. McMahon CG, Abdo C, Incrocci L, Perelman M, Rowland D, Waldinger M, Xin ZC. Disorders of orgasm and ejaculation in men. J Sex Med 2004;1:58-65. [CrossRef]

20. Giuliano F, Clément P. Serotonin and Premature Ejaculation: From Physiology to Patient Management. Eur Urol 2006;50:45466. [CrossRef]

21. Althof SE, Abdo CHN, Dean J, Hackett G, McCabe M, McMahon CG, et al. International Society for Sexual Medicine's Guidelines for the Diagnosis and Treatment of Premature Ejaculation. J Sex Med 2010;7:2947-69. [CrossRef]

22. Hatzimouratidis K, Amar E, Eardley I, Giuliano F, Hatzichristou $\mathrm{D}$, Montorsi F, et al. Guidelines on male sexual dysfunction: erectile dysfunction and premature ejaculation. Eur Urol 2010;57:804-14. [CrossRef]

23. Semans JH. Premature ejaculation: A new approach. South Med J 1956;49:353-8. [CrossRef]

24. De Carufel F, Trudel G. Effects of a new functional-sexological treatment for premature ejaculation. J Sex Marital Ther 2006;32:97-114. [CrossRef]

25. Tanrikut C, Goldstein M, Rosoff JS, Lee RK, Nelson CJ, Mulhall $\mathrm{JP}$. Varicocele as a risk factor for androgen deficiency and effect of repair. BJU Int 2011;108:1480-4. [CrossRef]

26. Alizadeh F, Rangzan N, Mohseni M, Hosseini S. Serum testosterone and gonadotropins levels in patients with premature ejaculation: A comparison with normal men. Adv Biomed Res 2014;3:6. [CrossRef]

27. Tanrikut C, McQuaid JW, Goldstein M. The impact of varicocele and varicocele repair on serum testosterone. Curr Opin Obstet Gynecol 2011;23:227-31. [CrossRef]

28. Li HC, Zhang LD, Gao M, Chong T, Deng Q, Yin J WZ. Spermatic vein ligation and intra-vaginal ejaculation latency. Zhonghua Nan Ke Xue 2014;20:531-5. https://pubmed.ncbi. nlm.nih.gov/25029860/

29. Hosseini SR, Mohseni MG, Alizadeh F. Impact of varicocelectomy on urine dopamine value in patients with premature ejaculation and varicocele. Andrologia 2019;51. [CrossRef] 